\title{
Communicable disease mortality trends and characteristics of infants in rural China, 1996-2015
}

Ke Wang ${ }^{1,2+}$, Liangcheng Xiang ${ }^{1,2+}$, Leni Kang ${ }^{1}$, Lei Miao ${ }^{1}$, Qi Li ${ }^{1}$, Xiaohong $\mathrm{Li}^{1}$, Jun Zhu ${ }^{1,2}$, Yanping Wang ${ }^{1,2}$, Yan Huang ${ }^{2,3^{*}}$ and Chunhua He $\mathrm{e}^{1,2^{*}}$

\begin{abstract}
Background: More attention should be paid to communicable disease-specific infant mortality rate (CD-IMR) in rural China. However, few studies have examined specific geographic patterns and trends in CD-IMR in these areas. Our aims were to assess the epidemiological distribution and trends in CD-IMR in rural China for the period 19962015.

Methods: We used data from China's Under-5 Child Mortality Surveillance System (U5CMSS). The time trends in communicable disease-specific IMR (CD-IMR) were assessed by Poisson regression model, and the proportion of total infant deaths due to communicable disease was assessed by the Cochran Armitage trend test. Differences in CD-IMR among and within geographic regions were assessed for significance using the Cochran-Mantel-Haenszel test.

Results: The overall CD-IMR fell by $86.0 \%$ from 1444.3 to 201.5 per 100,000 live births in rural mainland China from 1996 to 2015. The proportion of total infant deaths related to communicable disease fell from 33.4 to $19.7 \%$. Using eastern rural areas as the reference, rate ratios (RRs) of IMR due to all communicable diseases ranged between 1.7 and 3.1 in central rural areas and between 4.4 and 9.8 in western areas during the four study intervals. Acute respiratory infection (ARI) accounted for $71 \%$ of deaths, followed by diarrhea and septicemia.

Conclusions: IMR due to communicable disease remains a major public health issue. ARI is the leading cause of mortality, followed by diarrhea. A regional gap remains in the risk of infant exposure to communicable disease in rural China. More attention should be paid to western rural areas.
\end{abstract}

Keywords: Communicable disease, Regional characteristics, Time trend, Infant mortality rate

\footnotetext{
* Correspondence: huangyan_hx@scu.edu.cn;

hechunhua@motherchildren.com

${ }^{\dagger}$ Ke Wang and Liangcheng Xiang contributed equally to this work.

${ }^{2}$ Key Laboratory of Birth Defects and Related Diseases of Women and

Children (Sichuan University), Ministry of Education, Chengdu, China

${ }^{1}$ National Office for Maternal and Child Health Surveillance of China,

Department of Pediatrics, West China Second University Hospital, Sichuan

University, No. 17, Section 3 South Renmin Road, Chengdu 610041, Sichuan,

China

Full list of author information is available at the end of the article
}

(C) The Author(s). 2020 Open Access This article is licensed under a Creative Commons Attribution 4.0 International License, which permits use, sharing, adaptation, distribution and reproduction in any medium or format, as long as you give appropriate credit to the original author(s) and the source, provide a link to the Creative Commons licence, and indicate if changes were made. The images or other third party material in this article are included in the article's Creative Commons licence, unless indicated otherwise in a credit line to the material. If material is not included in the article's Creative Commons licence and your intended use is not permitted by statutory regulation or exceeds the permitted use, you will need to obtain permission directly from the copyright holder. To view a copy of this licence, visit http://creativecommons.org/licenses/by/4.0/ The Creative Commons Public Domain Dedication waiver (http://creativecommons.org/publicdomain/zero/1.0/) applies to the data made available in this article, unless otherwise stated in a credit line to the data. 


\section{Background}

In 2015, China and other nations entered a new phase of development underpinned by the Sustainable Development Goals (SDGs). SDG 3 proposes to end preventable death of newborns and children under 5 years of age and to end epidemics or communicable diseases such as AIDS, tuberculosis, malaria and water-borne diseases by 2030 [1].

Over the last 20 years, China has experienced a substantial decline in under-five mortality. However, the threat of communicable diseases persists for children under 5 years, with communicable diseases remaining a leading source of morbidity and mortality. In 2015, approximately $19 \%$ of deaths among children 5 years of age were due to communicable disease [2]. Deaths caused by communicable disease can be avoided through prevention and treatment, education, immunization campaigns, and reproductive health care. It is particularly important to target such prevention and intervention efforts at infants, since infant deaths account for $75 \%$ of deaths among children under 5 years of age in China [3]. Thus, reducing infant deaths due to communicable disease may be the most effective way to achieve SDG 3.

Between 1996 and 2015, IMR fell in China from 36.0 [4] to 8.1 per 1000 live births [5], which is lower than in most developing countries [6]. However, great disparities in IMR remain because of geographical differences and imbalanced economic development. For example, during 1996-2015, the mortality rate due to pneumonia among children under 5 years of age was higher in rural areas than in urban areas [7]. It is likely that a similar disparity holds for infants. Therefore, more attention should be paid to communicable disease-specific IMR (CD-IMR) in rural China. However, few studies have examined specific geographic patterns and trends in communicable disease-specific IMR in these areas.

The present study examined these patterns and trends for the period 1996-2015, with the aim of providing evidence for effective interventions and child health policy to improve infant health in rural China and potentially other developing countries.

\section{Methods}

\section{Data sources}

Data in this study were taken from the Under-5 Child Mortality Surveillance System (U5CMSS), established in the 1990s by the Chinese Ministry of Health. This population-based surveillance system collects data from 31 provinces in Mainland China (excluding Hong Kong, Macao and Taiwan), which established 123 surveillance sites (districts/counties) before 2009, and increased to 334 sites from 2009 onwards. U5CMSS came to its current structure in 2013, covering 334 sites with a surveillance population of 47.1 million. The mainland of China was divided into three geographic regions (i.e., eastern, central, and western regions) based on the criteria from the National Development and Reform Commission of China, and each region was further stratified into urban and rural areas, according to the criteria used in the National Health Services Survey and the administrative division codes published by the National Bureau of Statistics. The geographical distribution of surveillance sites in the three geographic regions of Mainland China has been reported [2]. More detailed information about sampling methods, subjects, data collection, and quality control in U5CMSS can be found in previous studies [7, 8]. In this study, U5CMSS data are available annually for the period 1996-2015.

\section{Verification of causes of death}

Cause of death was determined from death certificates in the case of children who died in hospital, from hospital-reported medical diagnoses in the case of children who used healthcare before death, or from verbal autopsies in the case of no medical record available. Doctors from township hospitals and community health service centers conducted verbal autopsies and deduced causes of death based on disease definitions in the $Z h u$ Futang Practice of Pediatrics. Causes of all deaths were confirmed by pediatricians at maternal and child health institutes at the county, municipal and provincial levels.

All deaths determined to be caused by communicable disease were included in the present study. Communicable diseases were classified according to the International classification of Diseases-10, including respiratory infection (ARI; H65-H66, J00-J22, J85, P23), diarrhea (A00-A09), septicemia (P36, A40-41), meningitis/encephalitis (A39, A83, A84-A87, G00, G03, G04) and other communicable diseases (A10-A32, A36, A38, A42-A82, A88-B04, B06B19, B25-B49, B55-B99, N30, N34, N39.0, N70-N73, U04).

\section{Statistical analysis}

Data from 123 representative sampling sites were used for analysis during 1996-2008 and data from 336 sites were used for analysis during 2009-2015. We defined CD-IMR as the number of deaths from communicable disease divided by the number of live births during the same time period. The IMR was adjusted by the 3-year moving average under-reporting rate [9] and expressed as deaths per 100,000 live births. The rate was separated by geographic region and weighted by the proportion of different geographic region population from the National Census to obtain the overall estimation.

The annual number of infants who died of specifictype communicable disease was relatively low. To obtain a reliable estimation, the entire study period of 1996- 
2015 was divided into four intervals: 1995-2000, 20012005, 2006-2010 and 2010-2015. Poisson regression was used to estimate the but Average Annual Percent Change (AAPC) in order to evaluate trends in CD-IMR at the national and regional levels. CD-IMRs between regions were compared through rate ratio (RR) and the associated 95\% confidence interval (CI), which were calculated using the Cochran-Mantel-Haenszel $(\mathrm{CMH})$ test [10]. The trend in proportion of total infant deaths due to communicable disease was analyzed using the Cochran-Armitage trend test [11]. All statistical analyses were performed using SAS 9.4. Statistical significance was assessed using two-tailed tests at an alpha level of 0.05 .

\section{Results}

Between 1996 and 2015, U5CMCC surveillance sites recorded 2,244,503 live births. The East, Middle and West China accounted for 21.7, 41.3 and $37.0 \%$ of total live births, respectively. Among them, there were 10,145 infant deaths due to communicable diseases. The East, Middle and West China accounted for 7.7, 28.6 and $63.7 \%$ of total infant mortality, respectively (Table S1).
CD-IMR fell by $86.0 \%$ in rural mainland China, from 1444.3 to 201.5 per 100,000 live births. The annual rate of decline was $10.5 \%(P<0.001)$. The proportion of communicable disease caused deaths in total infant mortality also decreased from $33.4 \%$ in 1996 to $19.7 \%$ in 2015 . This proportion decreased continuously over the last 20 years of the study period, with fluctuation during the last 10 years. The CD-IMR decreased in the three regions of rural China as well as in rural regions across the entire mainland. The IMR was highest in western rural areas and lowest in eastern rural areas (Fig. 1).

During the study period, ARI, diarrhea and septicemia were the top three communicable diseases causing infant mortality in eastern, central and western rural areas of China, as well as in rural regions across the entire Mainland China. Nationwide, ARI, diarrhea and septicemia accounted for $\sim 71 \%, \sim 17$ and $7 \%$ of infant deaths due to communicable disease in rural areas, and these proportions did not vary significantly over the study period. The proportion of ARI and its time trend in rural areas of the three regions were similar to the results in rural areas across the Mainland China. The second most frequent communicable disease caused infant mortality was

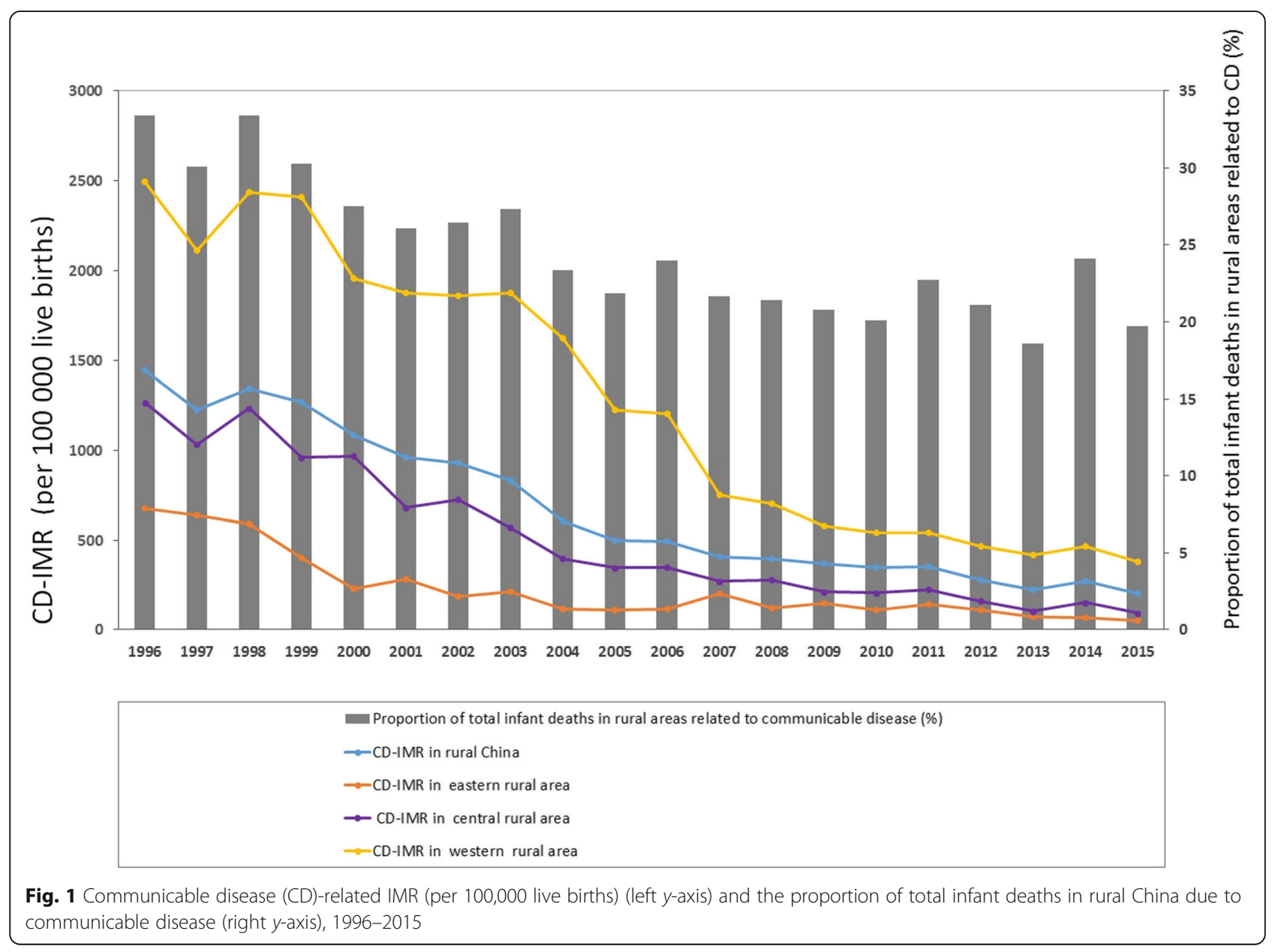



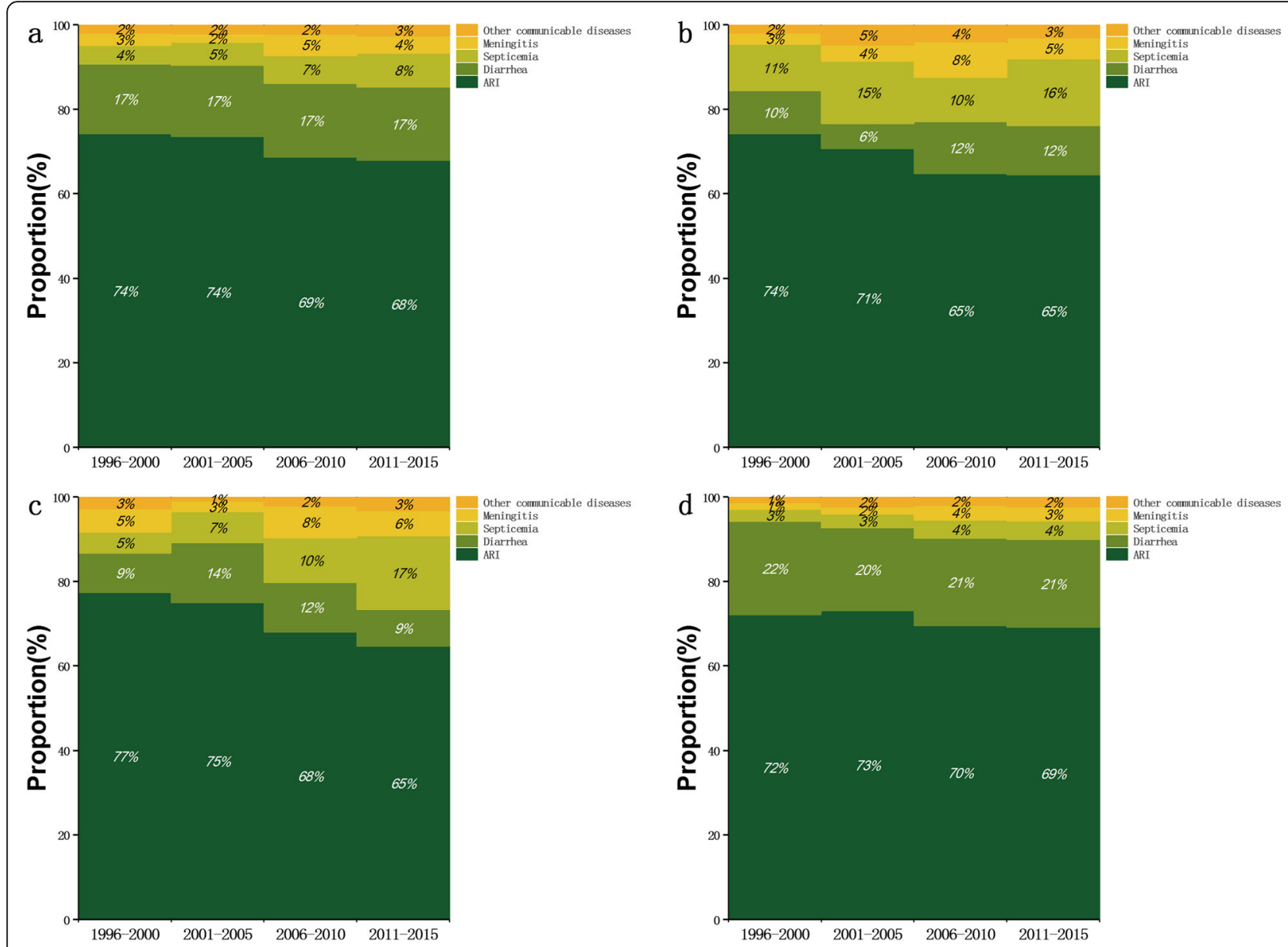

Fig. 2 Proportion of communicable disease-related deaths due to specific diseases (a) nationwide in rural regions, $\mathbf{b}$ in eastern rural regions, $\mathbf{c}$ in central rural regions or (d) in western rural regions for four intervals between 1996 and 2015

septicemia in eastern rural areas, and diarrhea in central and western rural areas. Diarrhea contributed to $6-12 \%$ of communicable disease-related infant deaths in eastern rural areas, $9-14 \%$ in central rural areas and $20-22 \%$ in western rural areas (Fig. 2).

During 1996-2000 and 2011-2015, ARI-, diarrheaand septicemia-specific IMRs decreased significantly in rural areas across mainland China by 81.0, 78.2 and $61.4 \%$, respectively. These decreases accounted for 75.8 , 16.3 and $3.4 \%$ of the overall decrease in CD-IMR. These three diseases caused IMR also decreased in eastern, central and western rural areas, mirroring the trend in total CD-IMR. Significant disparities among disease specific IMRs were observed among rural areas in different regions. Generally, the highest rates were observed in western rural areas and the lowest in eastern rural areas (Fig. 3).

Using eastern rural areas as the reference, RRs of CDIMR ranged between 1.7 and 3.1 in central rural areas and between 4.4 and 9.8 in western areas during the four study intervals. RRs peaked in 2001-2005, which RR was
3.1 for central areas and 9.8 for western areas. These RRs decreased to 1.7 and 5.2 in 2011-2015, respectively. The time trend of RRs for IMR due to ARI and diarrhea was similar to the time trend of all communicable diseases. Differences in septicemia- or meningitis-specific IMR in rural areas of different regions did not show obvious correlation with ARI- or diarrhea-specific IMR (Table 1).

\section{Discussion}

In the period of 1996-2015, the infant mortality due to communicable diseases has decreased significantly. Our data suggests that the overall CD-IMR in rural Mainland China has declined at an annual rate of $10.4 \%$, from 1444.3 per 100,000 live births in 1995 to 201.5 per 100 , 000 live births in 2015. This decline may be attributed to rapid economic growth, reflected in the $752.0 \%$ increase in domestic product per capita during the same period $[12,13]$. This growth has driven improvement in child health service infrastructure, pediatrician training, transportation condition, and education for girls. In parallel, 

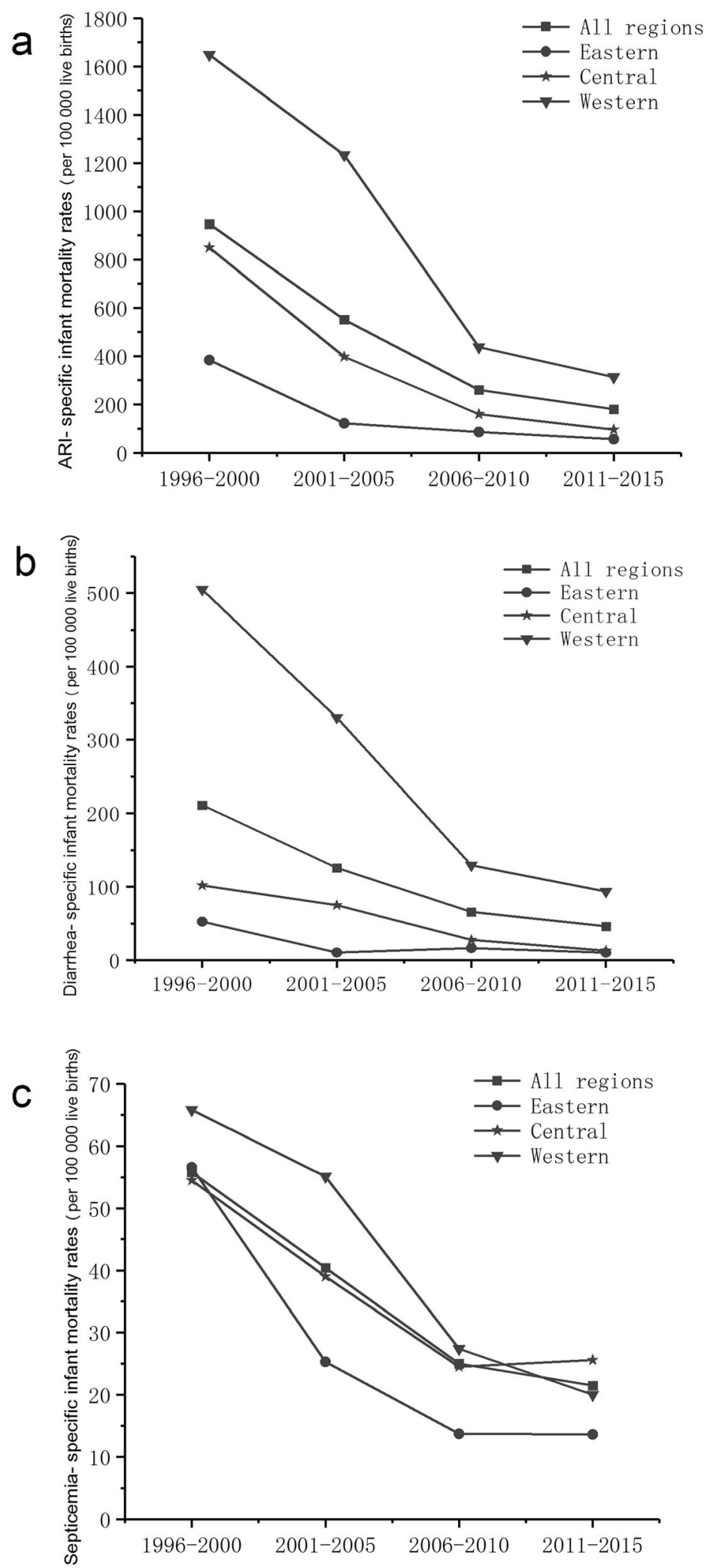

Fig. 3 Communicable disease-specific infant mortality rates in nationwide rural regions, eastern rural regions, central rural regions and western rural regions between 1996 and 2015. a ARI-specific infant mortality rate, b Diarrhea-specific infant mortality rate, c Septicemia-specific infant mortality rate 
Table 1 Rate ratio -based comparison of communicable disease-specific IMRs between different rural regions in China

\begin{tabular}{|c|c|c|c|c|c|}
\hline \multirow{2}{*}{$\begin{array}{l}\text { Rural regions } \\
\text { and time } \\
\text { period }\end{array}$} & \multicolumn{5}{|c|}{ Rate ratio of communicable disease-specific IMRs between different regions } \\
\hline & All diseases & ARI & Diarrhea & Septicemia & Meningitis \\
\hline \multicolumn{6}{|c|}{ Central vs. Eastern } \\
\hline $1996-2000$ & $2.1(1.9,2.4)$ & $2.2(1.9,2.6)$ & $1.9(1.3,2.9)$ & $1.0(0.6,1.5)$ & $4.2(2.0,8.9)$ \\
\hline $2001-2005$ & $3.1(2.5,3.8)$ & $3.3(2.6,4.2)$ & $7.8(3.4,17.9)$ & $1.5(0.9,2.7)$ & $2.1(0.7,6.2)$ \\
\hline $2006-2010$ & $1.8(1.5,2.1)$ & $1.9(1.5,2.3)$ & $1.7(1.0,2.7)$ & $1.8(1.1,3.1)$ & $1.6(0.9,2.9)$ \\
\hline $2011-2015$ & $1.7(1.5,2.0)$ & $1.7(1.4,2.1)$ & $1.3(0.8,2.1)$ & $1.9(1.3,2.7)$ & $2.1(1.1,4.2)$ \\
\hline \multicolumn{6}{|c|}{ Western vs. Eastern } \\
\hline 1996-2000 & $4.4(3.9,5.0)$ & $4.3(3.7,5.0)$ & $9.5(6.6,13.8)$ & $1.2(0.7,1.8)$ & $2.3(1.0,5.1)$ \\
\hline 2001-2005 & $9.8(8.1,12.0)$ & $10.2(8.1,12.9)$ & $34.6(15.4,77.8)$ & $2.2(1.2,3.9)$ & $4.4(1.5,12.8)$ \\
\hline 2006-2010 & $4.8(4.1,5.6)$ & $5.1(4.2,6.2)$ & $7.9(5.0,12.2)$ & $2.1(1.2,3.5)$ & $2.0(1.1,3.6)$ \\
\hline 2011-2015 & $5.2(4.5,6.0)$ & $5.6(4.7,6.7)$ & $9.4(6.2,14.2)$ & $1.5(1.0,2.2)$ & $3.7(1.9,7.2)$ \\
\hline
\end{tabular}

children's accessibility to health services has improved. For example, the percentage of children younger than 3 years covered by systematic health management expanded from $61.4 \%$ in 1996 to $87.0 \%$ in 2012 [14] (Additional file 1: Fig. S1). Implementation of major policies and programs has also contributed to the decline in under-5 mortality. For example, the New Rural Cooperative Medical System implemented in 2003 has reduced the rural residents' expenses on hospitalization and improved the utilization of inpatient services for communicable diseases among children. Government programs in the 1990s to improve drinking water quality and lavatory hygiene may have helped reduce diarrhea-specific IMR. Several studies suggested that the program of integrated management of childhood illness, implemented in 1998, has contributed to the reduction in under-5 mortality related to communicable diseases [15-19]. It is likely that the reduction also reflects the success of other public health programs, such as programs to vaccinate infants against communicable diseases such as tuberculosis, syphilis, hepatitis B virus, and maternal-child transmission of human immunodeficiency virus (HIV).

Communicable diseases are easier to prevent and control than congenital and chronic diseases. This likely helps explain the drastic reduction of CD-IMR in our study. Nevertheless, the proportion has remained relatively high at around $20 \%$, over the last 10 years. Health departments and the public health community in general should realize that communicable disease remains a leading cause of mortality among children younger than 1 year.

Our results indicate substantial regional differences in communicable disease-specific IMRs. Relative to eastern regions, the adjusted RR of IMR in western regions was more than 4 throughout the study period, while the adjusted RR in central regions was 1.7-3.1. These findings are consistent with results of previous work [20] and with the broader literature on the persistence of children's health disparities in developed and underdeveloped countries [21-25]. Such persistence may reflect socioeconomic inequalities and poor healthcare [26-29]. In China, eastern regions are generally the most developed, followed by central and western regions. Unequal economic development may contribute to the differences in CD-IMRs observed in the present study. The parents of many children living in rural areas, especially in western rural regions, have only basic education, so they may lack the information and knowledge necessary to prevent and control communicable diseases [30]. They may also be unable to accurately recognize or assess communicable disease risk on their own, thereby increasing the possibility of mortality. Another risk factor for infant mortality in rural regions may be inadequate healthcare resources [31]. A national healthcare survey in 2012 reported 9.56 healthcare workers per 1000 in township hospitals and 3.86 healthcare workers per 1000 in rural clinics in eastern regions, and the corresponding numbers in western regions were 7.41 and 3.28 [32]. We observed a greater reduction in CD-IMR in eastern rural regions than in central or western rural regions in 19962006, consistent with previous work [7]. Several factors may explain this geographic difference, including a more developed economy, greater integration of children into the healthcare system, higher per capita net income of rural households, modernized pediatric infrastructure and transportation, and higher education level for women. In 2006-2015, the gap between eastern rural regions and rural regions in the rest of the country narrowed. The improved situation in central and western regions may reflect contributions from the integrated management of childhood diseases; the Great Western Development Strategy, which included construction of health infrastructure and pediatrician capacity-building and of course overall economic development. 
Throughout the study period, ARI accounted for 68$74 \%$ of communicable disease-related infant mortality. This is consistent with previous study [33] reporting that ARI such as pneumonia is the leading cause of mortality among children younger than 1 year with immature respiratory and immune systems. The proportion of CDIMR due to diarrhea was $17 \%$ in China from 1996 to 2015. The relatively low proportion of deaths due to diarrhea likely reflects the success of a Chinese government program in the 1990s to improve drinking water quality and lavatory hygiene. This program increased the percentage of the population with access to clean water from 43.2 to $74.6 \%$ between 1995 and 2012, and the percentage of the population with access to sanitary latrines increased from 39.8 to $71.7 \%$ between 1999 and 2012 [34]. However, a unique insight that emerges from our analysis is that, throughout the study period, the rates of mortality due to ARI or diarrhea were higher in central and western rural regions of China than in eastern rural regions. We also found septicemia and meningitis to be the relatively important causes of death related to communicable disease, and the rates of such deaths were higher in western rural regions. Therefore, implementing more child survival policies, resources, and programs, especially in central and western regions, should be a priority in order to reduce avoidable deaths. For example, programs such as health education should be strengthened to help parents recognize and prevent ARI, diarrhea, septicemia and meningitis early. A disease monitoring network should be established for collecting data on disease-related deaths and risk factors. Fasttrack pathways should be established for treatment of disease and for referral of critically ill under-five children.

Besides, the new surveillance sites were established in 2007 with rigorous training for the recruited employee. After 2 years of test run, U5CMCC assessed the data quality from the new sites in 2009. After meeting U5CMCC standard, the data from new sites were used to analyze CD-IMR. The data from all surveillance sites maintain a good representation at national and regional level. We compared the mortality rate from the surveillance sites established before 2009 with mortality rate from all surveillance sites and found statistically significant differences in rates between the two data sets in 2012 and 2015 (see the Table S2 for yearly 261 comparison), however the entity of the differences allow for the use of the data.

The results in this study should be interpreted with caution. Since the study is based on a sample survey, the results have some sampling error compared to the census. Communicable diseases were diagnosed based mainly on verbal autopsy or clinical symptoms, which may increase risk of misdiagnosis. Nevertheless, $87 \%$ of the infants included in our analysis received medical treatment before death and so were diagnosed by specialists in healthcare facilities.

\section{Conclusion}

The rate of mortality due to communicable disease declined among infants in rural areas of China from 1996 to 2015. This likely reflects the country's rapid economic growth as well as its implementation of policies and programs to eliminate poverty and improve child health. Nevertheless, infant mortality due to communicable disease remains a major public health problem. Communicable disease-specific IMR is higher in western rural regions than in eastern rural regions. In rural regions, ARI remains the leading cause of mortality among infants, followed by diarrhea and septicemia. In China, expansion of public health policies, capital investment, health education, and access to medical resources--especially in western rural regions--should be a priority for reducing and ending preventable deaths from communicable disease in infants.

\section{Supplementary information}

Supplementary information accompanies this paper at https://doi.org/10. 1186/s12889-020-08486-y.

Additional file 1: Figure S1. (a) Per capita net income of rural residents (RMB/yr) and ARI-specific infant mortality rate, (b) Proportion of children under 3 covered by systematic health management and ARI-specific infant mortality rate.

Additional file 2: Table S1. The basic data of infant communicable disease mortality in rural China, 1996-2015.

Additional file 3: Table S2. The comparison of communicable diseasespecific IMR between 123 and 334 surveillance sites.

\section{Abbreviations}

IMR: Infant mortality rate; CD-IMR: Communicable disease-specific IMR; ARI: Acute respiratory infection; SDGs: Sustainable Development Goals; U5CMSS: Under-5 Child Mortality Surveillance System; RR: Rate ratio;

$\mathrm{Cl}$ : Confidence interval; CMH: Cochran-Mantel-Haenzel

\section{Acknowledgments}

We thank the countless health workers who have contributed to data collection in the MCHSS.

\section{Authors' contributions}

$\mathrm{CHH}$ contributed to study design. YH contributed to revise the manuscript. All authors including LNK, LM, QL, XHL, JZ and YPW contributed to data acquisition. KW and LCX analyzed data and wrote the manuscript, which all authors reviewed. The author(s) read and approve the final manuscript.

\section{Funding}

This study was funded by the National Health and Family Planning Commission of The People's Republic of China (grants QT2003-009 and 05wsb-02), the National Science and Technology Basic Work Project of the Ministry of Science and Technology of China (grant 2014FY110700), and UNICEF. The funding contributed to data acquisition and quality control.

\section{Availability of data and materials}

The datasets used and/or analyzed during the current study are available from the corresponding author on reasonable request. 


\section{Ethics approval and consent to participate}

The study was approved by the bioethical committee of Ethics Committee of West China Second University Hospital, Sichuan University.

\section{Consent for publication}

Not applicable.

\section{Competing interests}

The authors declare that they have no competing interests.

\section{Author details}

'National Office for Maternal and Child Health Surveillance of China, Department of Pediatrics, West China Second University Hospital, Sichuan University, No. 17, Section 3 South Renmin Road, Chengdu 610041, Sichuan, China. ${ }^{2}$ Key Laboratory of Birth Defects and Related Diseases of Women and Children (Sichuan University), Ministry of Education, Chengdu, China. ${ }^{3}$ Department of Obstetrics, West China Second University Hospital, Sichuan University, Chengdu, China.

\section{Received: 31 August 2018 Accepted: 9 March 2020}

Published online: 06 April 2020

\section{References}

1. SDG 3: Ensure healthy lives and promote wellbeing for all at all ages. http:// www.who.int/sdg/targets/en/. Accessed 4 Apr 2018.

2. He C, Liu L, Chu Y, Perin J, Dai L, Li X, Miao L, Kang L, Li Q, Scherpbier R, et al. National and subnational all-cause and cause-specific child mortality in China, 1996-2015: a systematic analysis with implications for the sustainable development goals. Lancet Glob Health. 2017:5(2):e186-97.

3. Wang $H$, Liddell CA, Coates MM, Mooney MD, Levitz CE, Schumacher AE, Apfel $\mathrm{H}$, lannarone $\mathrm{M}$, Phillips B, Lofgren $\mathrm{KT}$, et al. Global, regional, and national levels of neonatal, infant, and under-5 mortality during 1990-2013: a systematic analysis for the Global Burden of Disease Study 2013. Lancet. 2014:384(9947):957-79.

4. Huang $R$. The changing rates and risk factors of infant mortality of China in 1991-2014. Popul Soc. 2016:32(3):67-75.

5. Statistical report of health and family planning in China in 2015. http:// www.nhfpc.gov.cn/guihuaxxs/s10748/201607/da7575d64fa04670b5f375 c87b6229b0.shtml.

6. Global Health Observatory country views. http://apps.who.int/gho/data/ node.country. Accessed 4 Apr 2018

7. Kang L, He C, Miao L, Liang J, Zhu J, Li X, Li Q, Wang Y. Geographic disparities in pneumonia-specific under-five mortality rates in mainland China from 1996 to 2015: a population-based study. Int J Infect Dis. 2017;59: 7-13.

8. Wang Y, Li X, Zhou M, Luo S, Liang J, Liddell CA, Coates MM, Gao Y, Wang L, He C, et al. Under-5 mortality in 2851 Chinese counties, 1996-2012: a subnational assessment of achieving MDG 4 goals in China. Lancet (London, England). 2016;387(10015):273-83.

9. Wang YP, Miao L, Dai L, Zhou GX, He CH, Li XH, Li Q, Li MR, Zhu J, Liang J. Mortality rate for children under 5 years of age in China from 1996 to 2006. Public Health. 2011;125(5):301-7.

10. Agresti A. Categorical data analysis. New York: Wiley; 1990.

11. RS R. Epidemiology principles and methods. Chengdu: Sichuan University press; 2004

12. China Statistical Yearbook 1997. http://data.stats.gov.cn/easyquery.htm?cn= C01\&zb=A0A0F04\&sj=1997. Accessed 4 Apr 2018.

13. China Statistical Yearbook 2016. http://data.stats.gov.cn/easyquery.htm?cn= C01\&zb=A0A0F04\&sj=2016. Accessed 4 Apr 2018.

14. China NBoSotPsRo. China statistical Yearbook 2013. Beijing: China Statistical Press; 2013.

15. Wang HYS, Teng H, Wang S, Wu Y. Analysis the effect of maternity and child health services project on reducing the mortality and morbidity rate in the poorest areas in China. Chin J Matern Child Health Care. 2003;18:395-9.

16. Dong ZQ. Strengthen the prevention and treatment of respiratory infections in children. Chin J Pediatr. 2000;38:597-8.

17. Black RE, Cousens S, Johnson HL, Lawn JE, Rudan I, Bassani DG, Jha P, Campbell H, Walker CF, Cibulskis R, et al. Global, regional, and national causes of child mortality in 2008: a systematic analysis. Lancet. 2010; 375(9730):1969-87.
18. Health EdoCJoR. The effectiveness of comprehensive management of child diseases. Chin J Reprod Health. 2008;19:280.

19. Zhang YFDY, Zhang SM. Health facility survey on basic equipments and drugs in implementation areas of integrated management of childhood illness (IMCI). Chin J Child Health Care. 2007;15:519.

20. Baldwin LMGD, Murowchick E, et al. Trends in perinatal and infant health disparities between rural American Indians and Alaska natives and rural whites. Am J Public Health. 2009;99:638-46.

21. Alexander GR, Wingate MS, Bader D, Kogan MD. The increasing racial disparity in infant mortality rates: composition and contributors to recent US trends. Am J Obstet Gynecol. 2008:198(1):51.e51-9.

22. Matijasevich A, Victora CG, Barros AJ, Santos IS, Marco PL, Albernaz EP Barros FC. Widening ethnic disparities in infant mortality in southern Brazil: comparison of 3 birth cohorts. Am J Public Health. 2008;98(4):692-68.

23. Gonzalez RRJ, Nien JK, et al. Tackling health inequities in Chile: maternal, newborn, infant, and child mortality between 1990 and 2004. Am J Public Health. 2009:99:1220-6.

24. Movahedi M, Hajarizadeh B, Rahimi A, Arshinchi M, Amirhosseini K, Haghdoost AA. Trends and geographical inequalities of the main health indicators for rural Iran. Health Policy Plan. 2009:24(3):229-37.

25. Laskar MS, Harada N. Trends and regional variations in infant mortality rates in Japan, 1973-1998. Public Health. 2005:119(7):659-63.

26. Pena R, Wall S, Persson LA. The effect of poverty, social inequity, and maternal education on infant mortality in Nicaragua, 1988-1993. Am J Public Health. 2000;90(1):64-9.

27. Feachem RG. Poverty and inequity: a proper focus for the new century. Bull World Health Organ. 2000;78(1):1-2.

28. Son MOJ, Choi YJ, et al. The effects of the parents' social class on infant and child death among 1995-2004 birth cohort in Korea. J Prev Med Public Health. 2006;39:469-76.

29. Jahan S. Poverty and infant mortality in the Easternern Mediterranean region: a meta-analysis. J Epidemiol Community Health. 2008;62:745-51.

30. Bryce J, Boschi-Pinto C, Shibuya K, Black RE. WHO estimates of the causes of death in children. Lancet (London, England). 2005;365(9465):1147-52.

31. Shi L, Macinko J, Starfield B, Xu J, Regan J, Politzer R, Wulu J. Primary care, infant mortality, and low birth weight in the states of the USA. J Epidemiol Community Health. 2004:58(5):374-80.

32. Center for Health Statistics and information M. Research on health services of primary health care facilities in China, 2008. Beijing: Peking Union Medical College Press; 2009

33. A Promise Renewed progress report 2013. http://www.unicef.org/ publications/files/APR_Progress_Report_2013_9_Sept_2013.pdf. Accessed 4 Apr 2018

34. China HMo. Health statistical Yearbook of China, 1st edn. China: Peking Union Medical College press; 2013

\section{Publisher's Note}

Springer Nature remains neutral with regard to jurisdictional claims in published maps and institutional affiliations.

Ready to submit your research? Choose BMC and benefit from:

- fast, convenient online submission

- thorough peer review by experienced researchers in your field

- rapid publication on acceptance

- support for research data, including large and complex data types

- gold Open Access which fosters wider collaboration and increased citations

- maximum visibility for your research: over $100 \mathrm{M}$ website views per year

At BMC, research is always in progress.

Learn more biomedcentral.com/submissions 